ARTIGOS / ARTICLES

DOI: $10.5433 / 1679-0383.2020 v 41 n 2 p 249$

\title{
O trabalho para mulheres egressas da licença maternidade: (re)pensando as transformações profissionais no contexto de educação
}

\author{
Work for women on maternity leave: (re) thinking about \\ professional changes in the context of education
}

\author{
Cristiano de Jesus Andrade ${ }^{1}$, Luci Praun ${ }^{2}$, Hilda Rosa Capelão Avoglia ${ }^{3}$
}

\begin{abstract}
Resumo
Este artigo objetiva analisar as percepções de mulheres egressas da licença maternidade sobre o trabalho, bem como compreender que transformações as vivências inerentes à maternagem geram em seus modos de serem trabalhadoras no contexto educacional. Adotou-se como método a pesquisa qualitativa com recorte transversal. Participaram da pesquisa 13 servidoras da área da educação, vinculadas no setor público de um município de Minas Gerais. Como técnica, utilizou de entrevistas semiestruturadas, as quais foram analisadas a partir da teoria dejouriana e de autores que com ela dialogam. Como resultados observou-se a ressignificação das participantes em meio aos conflitos no egresso ao trabalho. As cisões entre espaço doméstico e espaço público, trabalho doméstico e trabalho assalariado, maternidade e trabalho, articulada ao conjunto de conflitos e dificuldades marcaram a separação entre mãe e bebê. Entretanto, o enfrentamento das condições desfavoráveis, os laços coletivos que estas situações puderam proporcionar, assim como as contribuições que a vivência da atividade de cuidado, são compreendidas de modo positivo.
\end{abstract}

Palavras-chave: Trabalho e maternidade. Divisão social e sexual do trabalho. Cuidado dos filhos.

\begin{abstract}
This article aims to analyze the perceptions of women graduating from maternity leave about work, as well as to understand what changes the experiences inherent to motherhood generate in their ways of being workers in the educational context. Qualitative research with a cross-sectional approach was adopted. Thirteen female civil servants in the education area, linked to the public sector of a municipality in Minas Gerais, participated in the research. As a technique, he used semi-structured
\end{abstract}

\footnotetext{
${ }^{1}$ Psicólogo. Doutorando no Programa de Pós-graduação em Psicologia da Saúde da Universidade Metodista de São Paulo (UMESP), São Paulo, São Paulo, Brasil. Professor do Curso de Graduação em Psicologia da Faculdade Pítágoras, Poços de Caldas, Minas Gerais, Brasil. E-mail: cristianoandradepsico@gmail.com

${ }^{2}$ Pós-doutorado pelo Instituto de Filosofia e Ciências Humanas da Universidade Estadual de Campinas (IFCH Unicamp), Campinas, São Paulo, Brasil. Professora Adjunta da Universidade Federal do Acre (UFAC), Rio Branco, Acre, Brasil.

${ }^{3}$ Doutorado pelo Instituto de Psicologia da Universidade de São Paulo (IPUSP), São Paulo, São Paulo, Brasil. Professora do Programa de Pós-graduação em Psicologia da Saúde da Universidade Metodista de São Paulo, São Paulo, São Paulo, Brasil. Professora do Mestrado Profissional em Psicologia, Desenvolvimento e Políticas Públicas da Universidade Católica de Santos (UNISANTOS), Santos, São Paulo, Brasil.
} 
interviews, which were analyzed based on the Dejourian theory and on authors who dialogue with it. As a result, it was observed that the participants had a new meaning in the midst of conflicts when they left work. The divisions between domestic and public space, domestic work and wage labor, maternity and work, linked to the set of conflicts and difficulties marked the separation between mother and baby. However, coping with unfavorable conditions, the collective bonds that these situations could provide, as well as the contributions that the experience of the care activity, are understood in a positive way.

Keywords: Work and maternity. Social and sexual division of labor. Childcare.

\section{Introdução}

Atualmente, inúmeras pesquisas buscam pensar as questões inerentes à maternidade no Brasil, no entanto, são escassos estudos que abordem a temática maternidade e trabalho. Entre os poucos evidenciados, encontram-se os de Garcia e Viecile (2018), que buscaram caracterizar as implicações na relação de mulheres com seu trabalho e rotina pessoal após a licença maternidade e Andrade, Praun e Avoglia (2018), que estudaram o sentido atribuído ao trabalho por mulheres egressas da licença maternidade. Andrade, Praun e Avoglia (2020) também analisaram a necessidade de se pensar nas estratégias defensivas utilizadas por mulheres frente à conciliação dos cuidados maternos com as atividades profissionais, uma vez que, quando se fala em conciliação da carreira com a maternidade, segundo Rodrigues e Sapucaia (2016), geralmente são as mulheres que mais desinvestem no trabalho produtivo. Compreendese que ainda hoje são estas as responsáveis principais pelos cuidados com os filhos, já que ainda não foi totalmente difundida a cultura da paternidade participativa, segundo informam Benincasa, Andrade e Souza (2020).

Frente ao exposto, este artigo busca contribuir para ampliar a reflexão sobre a temática, uma vez que, o que se evidencia é uma pequena quantidade de trabalhos sobre os impactos subjetivos que se desdobram do confronto e implicações entre a maternidade e a necessidade de retorno regular às atividades do trabalho fora de casa.

Para fins de aprofundamento e melhor compreensão da pesquisa, será desenvolvida uma fundamentação teórica visando problematizar inicialmente a dicotomia trabalho $\mathrm{x}$ maternidade, analisando as vivências permeadas pelo fim da licença maternidade, para que a posteriori sejam (re)pensadas as vivências de tornar-se mãe com a conciliação do trabalho produtivo em classes específicas, como as profissionais de educação.

\section{Maternidade e carreira}

A maternidade é um processo que uma parcela importante das mulheres vivencia. Até a realização do Censo de 2010, do Instituto Brasileiro de Geografia e Estatística (IBGE), $68,8 \%$ das mulheres brasileiras com 15 anos ou mais já tiveram pelo menos um filho (IBGE, 2010).

Beauvoir (1980), ao tratar sobre a maternidade, salienta o quanto o desenvolvimento das diferentes possibilidades de controle de natalidade, inseriu-a no campo da escolha. A ampliação dos métodos contraceptivos permitiu à mulher, potencialmente, a possibilidade de livremente assumir gerar ou não um bebê, ainda que persista e imponha-se a ela a ideia de maternidade como vocação natural.

No mesmo passo seguem os desafios resultantes do papel destinado histórica e socialmente à mulher. Por um lado, seja por sua livre escolha ou não, a ela é socialmente reservado o cuidado dos filhos e o trabalho doméstico (HIRATA, 2018). Por outro, seja pelas exigências impostas pela sobrevivência e/ou pelo desejo de, ao romper com os limites do espaço privado da família, inserir-se na vida pública. Ser mãe implica, na maioria das vezes, conciliar maternidade e atividade profissional (GARCIA; VIECILE, 2018). 
No Brasil, conforme o Censo de 2010, quando nosso olhar volta-se para a inserção no mercado de trabalho, pode se observar que $48 \%$ das mulheres com 16 anos ou mais, que exercem alguma ocupação, possuem pelo menos um filho vivo (IBGE, 2010).

Uma parcela dessas mulheres, que possui vínculo contratual formal com o trabalho, tem direito à licença maternidade, que incide entre o período final da gestação e os primeiros meses de vida do bebê. A legislação sobre o tema data de 1943, com a promulgação da CLT - Consolidação das Leis do Trabalho (BRASIL, 1943). Desde então, ao longo dos anos, a lei sofreu alterações, particularmente no que diz respeito ao tempo de afastamento da mãe de suas atividades profissionais, sendo que as normas em vigor preveem o afastamento do trabalho em um período que varia entre 120 e 180 dias (GARCIA; VIECILE, 2018). No caso específico do serviço público (onde as participantes deste estudo desenvolvem suas atividades profissionais), é válido o afastamento por 180 dias.

Para Andrade, Praun e Avoglia (2020), o período de licença maternidade tende a desencadear nestas mulheres processos de sofrimento psíquico. Este sofrimento, por sua vez, resulta de fatores diferenciados presentes na vida de cada uma dessas mães. No entanto, este se desdobra fundamentalmente do sentimento de incapacidade, significado socialmente e interiorizado pelas mães trabalhadoras, diante da necessidade de conciliar maternidade e vida profissional. E por tal sofrimento ser uma vivência quase que comum às mulheres, mães e trabalhadoras é que os autores (ANDRADE; PRAUN; AVOGLIA, 2020) salientam a importância que tais mulheres desenvolvam estratégias defensivas para lidarem com tal fenômeno. Uma vez que, conforme afirma Dejours (2012), sofrimento que não é elaborado pode vir a se configurar como adoecimento.

Neste momento, faz-se necessário trazer para o debate as mulheres que realizam dinâmica de trabalho em profissões específicas, como as profissionais de educação, público adotado para estudo nesta pesquisa.

\section{Maternidade e trabalho na perspectiva} de mulheres educadoras

Ainda que de modo incipiente, pesquisas têm sido produzidas buscando refletir a relação entre o trabalho feminino e o processo da maternidade na perspectiva de mulheres profissionais de educação. Krause (2017) realizou um estudo com 49 servidoras públicas a fim de identificar a realidade do retorno ao trabalho após a licença maternidade, identificando que as mulheres apresentam sentimento de vulnerabilidade: $70 \%$ delas demonstraram possuir sentimentos negativos relacionados ao trabalho.

Fabbro e Heloani (2010) realizaram uma pesquisa na qual objetivaram identificar a relação entre o trabalho de docência universitária e o nascimento do primeiro filho. Os autores entrevistaram cinco professoras de uma universidade pública de São Paulo que já haviam retornado ao trabalho após o nascimento do bebê. Os resultados da pesquisa permitiram demonstrar a coexistência de dois papéis na identidade das mulheres: o clássico de mãe e esposa, e os papéis mais recentes que envolvem o trabalho formal, o reconhecimento e a construção de uma carreira de prestígio. Porém, o conhecimento produzido pelos autores Fabbro e Heloani (2010) permite perceber que a vivência do papel materno influencia na carreira das mulheres de forma bastante significativa, a ponto de fazer com que repensem a continuidade e o valor profissional que vinham exercendo, antes tão expressivo e significativo.

No estudo de Vanalli e Barham (2012), foram entrevistadas 40 professoras de todos os níveis (infantil, fundamental e médio) da rede pública de educação, com filhos de até dois anos, com o objetivo de investigar as vivências e as percepções destas mulheres em relação ao seu retorno ao trabalho após a licença maternidade. Contudo, a pesquisa das autoras limitou-se a estudar a percepção das entrevistadas no que tange ao relacionamento com o cônjuge, envolvimento familiar do casal e a presença da rede de apoio que auxiliam nas demandas domésticas e nos cuidados com o bebê. 
Também no contexto dos dilemas enfrentados pelas mulheres que passam a desempenhar as funções materna e profissional, pesquisas realizadas por Rocha-Coutinho e Coutinho (2011) apontam para o fato de que tanto homens como mulheres ainda trazem a crença de que a provisão financeira da família é de responsabilidade do homem, e os filhos e trabalhos domésticos são de responsabilidade da mulher. Isto impacta em que, não obstante realizarem a mesma carga horária de trabalho formal fora do âmbito doméstico, as mulheres ainda dedicam mais tempo às atividades domésticas do que seus companheiros. Este fenômeno social também foi identificado nas pesquisas realizadas por Hirata (2018) e Instituto de Pesquisa Econômica Aplicada - IPEA (2016, p. 6) que evidenciam que as mulheres, mesmo quando estão empregadas, realizam 2,5 vezes mais tarefas domésticas e de cuidados do que os homens.

Sendo assim, verifica-se que a desigualdade no compartilhamento das tarefas domésticas, no cuidado para com os filhos, na ascensão profissional e socioeconômica e na remuneração financeira pode contribuir para que exista um sentimento de insatisfação nestas mulheres. Além disso, restringe a possibilidade de a mulher aumentar o número de horas dedicadas à busca por formação acadêmica ou especialização técnica.

Neste sentido, Benincasa, Andrade e Souza (2020) apontam o compartilhamento das tarefas domésticas, bem como o cuidado com os filhos pelos companheiros destas mulheres mães/ profissionais como condição fundante para que possam exercer suas atividades profissionais de modo satisfatório, indicando ser cada vez mais necessário o exercício da paternidade participativa.

Rodrigues e Sapucaia (2016) ilustram esta realidade, afirmando que a cada vez que uma mulher gasta uma hora cuidando dos filhos, fazendo comida ou lavando roupas, ela se afasta ainda mais da potencialidade de absorver papéis não domésticos, tanto profissionais como públicos.

Pensando no trabalho feminino, um problema recorrente, conforme aponta Ávila (2016), diz respeito à falta de reconhecimento das atividades das trabalhadoras, especialmente no trabalho de cuidado, ou atividades domésticas, desconsiderando-se, muitas vezes, que as atividades relacionadas ao cuidado com o outro implicam efetivamente em trabalho.

Lima (2012) coaduna com o já defendido por Ávila (2016), uma vez que acredita que a naturalização do ato de cuidar impede que o cuidar seja percebido e reconhecido como trabalho. Impede que se observe que é nesta experiência do trabalhar que a forma de cuidar se aperfeiçoa, não simplesmente pela boa vontade, mas por condições organizacionais favoráveis.

Em outras palavras, observando a relação que se desdobra do conflito entre maternidade e inserção no mercado de trabalho apropriando-se da perspectiva dejouriana (a teoria que será utilizada para análise dos dados obtidos nesta pesquisa), o que hoje ambivalentemente é compreendido como perda, representada pelo sofrimento em detrimento do elevado número de atividades a realizarem e dos pormenores cotidianos que incluem a separação do bebê, pode ser ressignificado como ganho, a depender dos suportes oferecidos à mãe trabalhadora dentro e fora do posto de trabalho.

\section{Objetivo}

Analisar as vivências de mulheres egressas da licença maternidade frente à conciliação dos papéis de mãe e trabalhadora, bem como compreender que transformações o vir a ser mãe as fazem experimentar como profissionais no contexto educacional.

\section{Método}

A pesquisa foi embasada no modelo qualitativo-descritivo, com recorte transversal. No contexto do método qualitativo aplicado à saúde é empregada a concepção trazida das Ciências Humanas, segundo a qual não se busca estudar o fenômeno em si, mas entender seu significado individual ou coletivo para a vida das pessoas (TURATO et al., 2019). O significado tem função 
estruturante, pois em torno do que as coisas significam, as pessoas organizam, de certo modo, suas vidas. $\mathrm{O}$ método qualitativo tem o fim comum de criar um modelo de entendimento profundo de ligações entre elementos, isto é, de falar de uma ordem que é invisível ao olhar comum. Salienta-se ainda o termo processo, caracterizando o método qualitativo como aquele que busca entender como o objeto de estudo acontece ou se manifesta, e não aquele que almeja o produto, isto é, os resultados finais matematicamente trabalhados (TURATO et al., 2019).

As pesquisas de caráter transversal podem ser definidas como estudos em que a exposição ao fator ou causa está presente ao efeito no mesmo momento ou intervalo de tempo analisado. Os estudos transversais descrevem uma situação ou fenômeno em um momento não definido, apenas representado pela presença de uma vivência, ou forma de existir, como as implicações vivenciadas por mulheres egressas de licença maternidade em seus postos de trabalho (CARNUT, 2019).

A escolha das participantes foi deliberada de uma amostra determinada, com características definidas (TURATO et al., 2019). A este modo, participaram 13 servidoras públicas concursadas de uma prefeitura situada no Sul de Minas Gerais, sendo que todas se encontram atuando junto à Secretaria Municipal de Educação, tendo sido entrevistadas: duas professoras (uma atuante no ensino fundamental e outra no ensino médio), duas supervisoras pedagógicas, duas berçaristas, duas merendeiras, uma auxiliar de serviços gerais (registro único de entrada em licença maternidade no período de 2014 e 2015), duas auxiliares de educação inclusiva, e duas auxiliares de desenvolvimento infantil.

Cabe salientar que a escolha de profissionais da educação como público a ser estudado devese a compreensão do dilema que vivenciam, uma vez que estas, ao fim da licença maternidade, deixam de cuidar de seus filhos enquanto mães, para retornarem ao posto de trabalho em que fazem função de educar e cuidar de outras crianças enquanto muitas vezes suas mães também estão trabalhando, provocando assim, a refletir sobre o modo como esta vivência dilemática é configurada em sua dinâmica psíquica.

A idade das mulheres trabalhadoras/mães participantes deste estudo varia entre 30 e 44 anos, sendo todas nascidas no estado de Minas Gerais. Entre as entrevistadas, 10 se autodeclararam brancas, outras duas declararam-se da cor preta e uma da cor parda, todas são casadas, tendo entre um(a) e três filhos(as), analisando que, entre estas, nove assinalaram ser mães de dois filhos(as), ao passo que três afirmam terem gerado três filhos(as) e apenas uma é mãe de um filho(a).

Quanto à religião, as trabalhadoras dividemse entre as que se declararam católicas (7) e evangélicas (6). No tocante à escolaridade, cinco relatam ter concluído o ensino superior, quatro apontam ter ensino superior com pós-graduação lato sensu, três possuem ensino médio completo e uma, ensino superior incompleto.

Entre a totalidade das 13 participantes, 11 afirmam que em suas casas a principal fonte de renda provém do marido. Duas das entrevistadas declararam ser elas mesmas as principais provedoras. Considerando que quatro relatam que, junto à renda do parceiro, somam de 1 a 3 salários mínimos ao mês, cinco relatam que a família recebe de 3 a 6 salários mínimos e quatro recebem de 6 a 9 salários mínimos.

É relevante pontuar que três participantes disseram dividir a casa com mais quatro habitantes, nove dividem com mais quatro habitantes e uma com mais dois habitantes.

Do ponto de vista da inserção e dinâmica de trabalho, as participantes possuem de 3 a 23 anos de serviço junto à prefeitura, salientando que a jornada de trabalho das mesmas varia entre quatro horas por dia (três participantes) e seis horas diárias (10 trabalhadoras). No tocante ao trabalho reprodutivo e/ou atividades domésticas, todas se ocupam de tal fazer, no entanto, 10 entrevistadas dividem as demandas domésticas com outros membros da família, ou com auxiliar contratada (apenas uma), porém, três não fazem esta divisão, já que assumem tal responsabilidades sem apoio. 
Quadro 1 - Descrição sociodemográfica das participantes.

\begin{tabular}{|c|c|c|c|c|c|c|c|c|}
\hline Part. & $\begin{array}{l}\text { Denominação/ } \\
\text { Profissão }\end{array}$ & Idade & Raça/Cor & Escolaridade & Religião & $\begin{array}{c}\text { Estado } \\
\text { civil }\end{array}$ & $\begin{array}{l}\text { Filhos } \\
\text { (as) }\end{array}$ & $\begin{array}{c}\text { Renda } \\
\text { familiar }\end{array}$ \\
\hline 1 & $\begin{array}{l}\text { Auxiliar de } \\
\text { desenvolvimento } \\
\text { infantil } 1\end{array}$ & 36 & Branca & $\begin{array}{l}\text { Pós-graduação } \\
\text { lato sensu } \\
\text { completa }\end{array}$ & Evangélica & Casada & 1 & $\begin{array}{l}6 \text { a } 9 \\
\text { salários } \\
\text { mínimos }\end{array}$ \\
\hline 2 & $\begin{array}{l}\text { Auxiliar de } \\
\text { desenvolvimento } \\
\text { infantil } 2\end{array}$ & 40 & Branca & $\begin{array}{l}\text { Ensino superior } \\
\text { completo }\end{array}$ & Católica & Casada & 2 & $\begin{array}{l}6 \text { a } 9 \\
\text { salários } \\
\text { mínimos }\end{array}$ \\
\hline 3 & $\begin{array}{l}\text { Auxiliar de } \\
\text { educação inclusiva }\end{array}$ & 30 & Preta & $\begin{array}{l}\text { Ensino superior } \\
\text { completo }\end{array}$ & Evangélica & Casada & 3 & $\begin{array}{l}3 \text { a } 6 \\
\text { salários } \\
\text { mínimos }\end{array}$ \\
\hline 4 & $\begin{array}{l}\text { Auxiliar de } \\
\text { educação inclusiva }\end{array}$ & 40 & Branca & $\begin{array}{l}\text { Pós-graduação } \\
\text { lato sensu } \\
\text { completa }\end{array}$ & Católica & Casada & 2 & $\begin{array}{l}3 \text { a } 6 \\
\text { salários } \\
\text { mínimos }\end{array}$ \\
\hline 5 & $\begin{array}{l}\text { Auxiliar de } \\
\text { serviços gerais }\end{array}$ & 34 & Preta & $\begin{array}{l}\text { Ensino médio } \\
\text { completo }\end{array}$ & Evangélica & Casada & 3 & $\begin{array}{l}1 \text { a } 3 \\
\text { salários } \\
\text { mínimos }\end{array}$ \\
\hline 6 & Berçarista 1 & 38 & Branca & $\begin{array}{l}\text { Ensino superior } \\
\text { completo }\end{array}$ & Católica & Casada & 2 & $\begin{array}{l}3 \text { a } 6 \\
\text { salários } \\
\text { mínimos }\end{array}$ \\
\hline 7 & Berçarista 2 & 39 & Branca & $\begin{array}{l}\text { Ensino superior } \\
\text { incompleto }\end{array}$ & Evangélica & Casada & 2 & $\begin{array}{l}1 \text { a } 3 \\
\text { salários } \\
\text { mínimos }\end{array}$ \\
\hline 8 & Merendeira 1 & 30 & Branca & $\begin{array}{l}\text { Ensino médio } \\
\text { completo }\end{array}$ & Evangélica & Casada & 3 & $\begin{array}{l}1 \text { a } 3 \\
\text { salários } \\
\text { mínimos }\end{array}$ \\
\hline 9 & Merendeira 2 & 34 & Branca & $\begin{array}{l}\text { Ensino médio } \\
\text { completo }\end{array}$ & Católica & Casada & 2 & $\begin{array}{l}1 \text { a } 3 \\
\text { salários } \\
\text { mínimos }\end{array}$ \\
\hline 10 & Professora 1 & 38 & Branca & $\begin{array}{l}\text { Ensino superior } \\
\text { completo }\end{array}$ & Evangélica & Casada & 2 & $\begin{array}{l}3 \text { a } 6 \\
\text { salários } \\
\text { mínimos }\end{array}$ \\
\hline 11 & Professora 2 & 36 & Branca & $\begin{array}{l}\text { Ensino superior } \\
\text { completo }\end{array}$ & Católica & Casada & 2 & $\begin{array}{l}6 \text { a } 9 \\
\text { salários } \\
\text { mínimos }\end{array}$ \\
\hline 12 & $\begin{array}{l}\text { Supervisora } \\
\text { pedagógica } 1\end{array}$ & 44 & Branca & $\begin{array}{l}\text { Pós-graduação } \\
\text { lato sensu } \\
\text { completa }\end{array}$ & Católica & Casada & 2 & $\begin{array}{l}6 \text { a } 9 \\
\text { salários } \\
\text { mínimos }\end{array}$ \\
\hline 13 & $\begin{array}{l}\text { Supervisora } \\
\text { pedagógica } 2\end{array}$ & 42 & Branca & $\begin{array}{l}\text { Pós-graduação } \\
\text { lato sensu } \\
\text { completa }\end{array}$ & Católica & Casada & 2 & $\begin{array}{l}1 \text { a } 3 \\
\text { salários } \\
\text { mínimos }\end{array}$ \\
\hline
\end{tabular}

Fonte: Autores

\section{Procedimentos}

Todas as participantes foram convidadas, considerados os critérios estabelecidos, por contato telefônico, onde detalhou-se o objetivo da pesquisa, bem como a importância das participações.
As entrevistas, com duração de cinquenta minutos cada, foram realizadas no consultório de um dos pesquisadores (Andrade), situado na região central da cidade.

A entrevista realizada em um único encontro, semidirigida, foi organizada a partir de 
um roteiro prévio de questões. Ressalta-se que a entrevista semidirigida foi escolhida para a coleta de dados por permitir que os resultados obtidos se mantenham dentro do enfoque da pesquisa e fornecendo, ao mesmo tempo, liberdade para que a participante exteriorize outras respostas relacionadas com a temática principal.

As entrevistas gravadas foram transcritas e a posteriori feita uma segunda escuta para conferir a fidedignidade dos dados da transcrição. Os dados foram analisados à luz do método de Análise de Conteúdo (BARDIN, 2016), uma vez que este visa obter, por procedimentos sistemáticos e objetivos de descrição, o teor das respostas, tentando compreender criticamente o sentido das mensagens, através de uma busca incessante por significações explícitas e ocultas (BARDIN, 2016).

Neste sentido, todo o conteúdo e a saturação das falas foram analisados, a partir dos seguintes procedimentos metodológicos: categorização, inferência, descrição e interpretação dos resultados (BARDIN, 2016).

Buscou-se realizar uma síntese categórica, priorizando os aspectos mais importantes das mensagens, reduzindo os dados repetitivos e agrupando-os em categorias temáticas, no qual foram nomeadas como Categorização das Informações. Essas categorias temáticas foram criadas para sistematizar os resultados obtidos (BARDIN, 2016).

É interessante salientar que entre estas categorias encontra-se o recorte que a seguir será apresentado.

Por fim, informamos ainda que a participação na pesquisa, por parte das entrevistadas, foi de livre escolha, precedida da assinatura do Termo de Consentimento Livre e Esclarecido (TCLE), tanto pela entrevistada como pelo pesquisador, com a garantia de sigilo sobre sua identificação, cabendo ainda salientar que o estudo foi aprovado pelo Comitê de Ética e Pesquisa vinculado à Universidade Metodista de São Paulo (UMESP). Também se solicitou a permissão para uso do gravador.

\section{Resultados e Discussão}

Antes de adentrar nos resultados, tornase relevante salientar que, para a preservação do anonimato das mulheres, optou-se por nomeá-las genericamente com o nome do cargo que ocupam nas instituições, acompanhado dos números 1 e 2. No entanto, salienta-se que, entre estas, a participante auxiliar de serviços gerais será a única a ser nomeada apenas com o número 1 , pois havia somente uma representante desta categoria no estudo.

Descrevemos, a seguir, a síntese dos relatos das participantes a partir das categorias do vir a ser mãe às implicações em "estar" trabalhadora, propondo refletir acerca das percepções de maternidade segundo o olhar das servidoras públicas, bem como visando compreender as implicações que tal fenômeno gera no processo de estar trabalhadora segundo mulheres servidoras públicas egressas da licença maternidade.

Por outro lado, a subcategoria maternidade como possibilidade de transformação profissional busca refletir sobre as possíveis transformações que a maternidade pode vir a gerar nas mulheres trabalhadoras, levando em consideração suas percepções antes e depois da gestação sobre o trabalhar, os pares e a instituição.

\section{Do vir a ser mãe às implicações em "estar" trabalhadora}

A fim de compreender tais achados, $a$ priori, cabe lembrar que, embora diversas teorias busquem definir a maternidade como um fenômeno meramente fisiológico, neste estudo, apoiados pela reflexão de Beauvoir (1980), busca-se compreender a maternidade como um fenômeno para além desta definição. Visando discutir de que modo a intensidade e o momento em que a vivenciam como sendo fatores diretamente relacionados às influências culturais do meio em que a mulher se encontra e também de sua história pessoal e afetiva.

A este modo, as participantes de maneira quase que geral expressaram falas que dialogam 
com as reflexões de Beauvoir (1980), no sentido que apresentaram o ser mãe como uma realização pessoal, uma experiência única dotada de sentido e afeto. No entanto, contatam a realidade e compreendem que vir a ser mãe não é um fenômeno que se desvela somente nutrido de prazer, mas ao contrário da ideia romântica e mitológica que se dita socialmente, tornar-se mãe dá trabalho. Para melhor compreensão desta articulação, seguem as falas literais advindas das entrevistas realizadas:

É ótimo ser mãe, eu adoro ser, mas acho que a gente precisa tirar um pouco daquela parte romântica. Porque o pessoal fala que é lindo ser mãe, que é maravilhoso. É, mas também é trabalhoso, e na verdade é muito cansativo, principalmente para a gente que além de tudo trabalha fora de casa. (Auxiliar de educação inclusiva 2).

É claro que dá trabalho, preciso conciliar tudo, filhos, casa e serviço, mas eu adoro ser mãe. (Berçarista 2).

Sempre quis ser mãe, só que antes de ser o desejo parece lindo, mas depois que a gente tem, claro é gostoso ser mãe, mas a gente vê que não é tão lindo assim, é pesado, não é fácil, principalmente porque a gente trabalha fora. Aperta muito mais a vida da gente, porque a gente passa a depender muito mais dos outros, não é fácil, mas é bom. (Auxiliar de educação inclusiva 1).

Para fins de compreensão, Dejours (2012) acredita que vivências dificultosas, conforme trouxeram as participantes em seus discursos neste estudo, podem se configurar em sofrimento e provocar irritabilidade, descontentamento, cansaço. Tal situação pode levá-las a descontar os reveses em familiares, tais como o cônjuge e até mesmo o filho amado. Embora as participantes anteriormente apresentadas não sinalizem descontar seu cansaço no bebê, nem no marido, parecem evidenciar o sentimento de divisão quanto à escolha pela maternidade, no sentido que afirmam compreender que é uma experiência boa, porém, que dá trabalho; promovendo, assim, uma reflexão na qual possa ser desmistificada a ideia romântica e mitológica, fruto de uma ditadura social inerente ao tornar-se mãe.

Aprofundando a análise, identifica-se que o fato de terem que conciliar as atribuições das atividades reprodutivas (atividades domésticas/ coisas de casa) com o trabalho produtivo (fora de casa) faz com que se sintam angustiadas, uma vez que não se veem amparadas e nem reconhecidas pelos companheiros e/ou maridos, já que este sentimento não aparece em nenhum discurso, além de que, ao mesmo tempo encontram-se desejosas por mais tempo junto aos filhos. Visto que, mediante as atividades realizadas, as participantes precisam engenhosamente encontrar um modo inteligente, porém subjetivo de dar conta destas múltiplas funções. Já que tal feito além de oferecer mais qualidade na relação mãe-bebê, faz também com que a mulher se sinta mais segura, conforme pode ser verificado abaixo no fragmento da entrevista:

É uma experiência linda, mas acho que ficou melhor ainda quando administrei o tempo para ficarmos mais juntos. Foi muito bom, tanto para mim quanto para meus filhos, porque dá uma segurança a mais para nós. (Supervisora pedagógica 1).

A mesma participante, por meio de suas vivências, compreende que se faz necessário realizar alguns ajustes na rotina diária, no sentido de poder dividir as tarefas para uma melhor administração do tempo, como afirma:

Eu entendi que sozinha não dá, a gente precisa fazer alguns acordos, porque parceria em casa é tudo. (Supervisora pedagógica 1).

Complementando a reflexão anteriormente citada, as participantes a seguir salientam a relevância da divisão das tarefas para a melhor dinâmica em conciliar trabalho produtivo, reprodutivo, maternidade e os papeis sociais como um todo, tal como afirmam:

Meu marido é peça fundamental, porque ele praticamente faz de tudo, mas não gosta de lavar louças (risos), mas ele dá banho, troca as 
crianças, fica com os meninos quando eu não estou, arruma a casa. Porque ele sabe que lá em casa não é só o trabalho da mulher, é um trabalho do conjunto, de nós dois. (Merendeira 1).

A maior parte é minha, mas a gente combina assim, eu fico com os cuidados da casa, limpeza e faço a janta. Ai ele me ajuda lavando a louça e no cuidado com os filhos, dá banho, ele é muito colaborativo, quando tem médico ele vai comigo. Então eu o vejo muito como meu parceiro nestas partes, o que me ajuda muito a conciliar minhas tarefas. (Berçarista 1).

Neste caso, as participantes Merendeira 1 e Berçarista 1 levam a compreender que para conseguir continuar realizando a atuação como mãe de modo satisfatório, bem como voltar à atividade profissional, é fundamental que sejam promovidos, como sugerem Garcia e Viecili (2018), rearranjos domésticos (divisão das tarefas no lar e com os filhos) e profissionais (empregos em tempo parcial para homens e mulheres com filhos pequenos), mudanças que, evidentemente, escapam da esfera individual e remetem à organização e apoio coletivo.

Diante do exposto, assim como defendem Benincasa, Andrade e Souza (2020), parece claro que o suporte advindo do companheiro no processo de divisão de tarefas domésticas é condição sine qua non para que tais mulheres possam melhor administrar sua dinâmica cotidiana no que concerne trabalho produtivo $\mathrm{x}$ reprodutivo e, assim, manter a saúde mental protegida. Visto que mais que inteligentes, precisam ser engenhosas e amparadas no que tange ao suporte social do marido e outros familiares. No entanto, assim como os achados obtidos por pesquisas de Rodrigues e Sapucaia (2016) e do Instituto de Pesquisa Econômica Aplicada (2016), as participantes demonstram se depararem com dificuldades na divisão das tarefas, salientando que os companheiros "não gostam muito" de realizarem atividades domésticas, talvez porque ainda na atualidade estas são representadas no imaginário social como "atividades de casa", portanto, "coisas de mulheres", conforme se verifica nos seguintes destaques:
Para piorar, meu marido não gosta muito de tarefas ligadas à casa, então acabava ficando tudo para mim. Apesar de que, com as crianças ele me ajudou e ainda me ajuda muito, acorda elas, arruma elas, dá café, leva para creche, à noite me ajuda dando banho, colocando para dormir. Então ele com as crianças acaba fazendo até mais que eu! Quando eu tenho que fazer alguma coisa lá em casa, ele sai com as crianças para eu fazer, então me ajuda muito neste sentido. (Berçarista 2).

Eu fico cuidando deles à noite e de manhã todos os dias; meu marido não têm me ajudado muito, porque trabalha de segunda a segunda, então me ajuda assim... dentro do possivel cuidar deles. Mas... as coisas de casa sou eu quem faz, porque não dá tempo para ele fazer. (Berçarista 2).

Buscando compreender as vivências identificadas nas verbalizações das participantes deste trabalho, torna-se relevante ressaltar que autores como Hirata (2018) defendem que ainda hoje a menor participação dos homens nas tarefas domésticas acontece devido ao fato de que estas atividades permanecem consideradas como essencialmente femininas, o que leva a se fortalecer a segregação por gênero.

Sendo assim, pode-se dizer que tais ideias, que podemos nomeá-las como disfuncionais, acabam por afetar diretamente as mulheres trabalhadoras participantes deste estudo. Uma vez que em seus discursos tal divisão de tarefas domésticas vem sendo representada como ajuda, em outras palavras, um apoio quase que gentil do parceiro e não como um trabalho que ao mesmo também é atribuído a desenvolver. Além de que, demonstraram não vislumbrar a divisão de tarefas como parte da responsabilidade paterna, chegando a justificarem que o fato de não as "atrapalharem" já pode ser considerado como um modo de "apoio" e, assim, não interfere negativamente em suas trajetórias, como pode ser identificado:

Meu marido mesmo já me dá esta ajuda, ou seja, não me atrapalha, não é bagunceiro, então já está bom. E além do que posso contar com ele para lavar uma louça, para dar banho 
nas crianças, então ele ajuda sim e me permite ser o que sou (risos). (Professora 2).

Mas depois que elas nasceram ai ele me ajudou. Me ajudou com pequenas coisas, porque eu sempre fiquei com a maior parte e tenho até hoje. Tem dia que brigo em casa dizendo que tem que me ajudar, porque ainda tenho um monte de coisa para fazer. (Supervisora pedagógica 2).

O que pega mesmo é ser dona de casa e mãe, tudo acaba ficando mais para gente, meu marido mesmo ajuda só a cuidar das crianças na hora de dar banho, ou coloca para dormir (risos), não ajuda mais não, mas às vezes coloco ele para frente e ele me ajuda. No fim tudo tem dado certo. (Professora 1).

Senti uma diferença de ajuda do primeiro para o segundo; no caso do segundo, meu marido ajuda, mas deixa a desejar. Me ajuda a dar banho nos dois, só que tem algo que eu não gosto, porque quando ele dá banho deixa os meninos meio molhados, então eu preciso ficar de sobreaviso, preciso ir lá secar porque não gosto que fique assim. (Merendeira 2).

Diante dos relatos apresentados pelas participantes, articulados com as reflexões de Dejours (2012), compreende-se que o trabalho, bem como os demais papeis exercidos pelas mulheres deveriam ser reconhecidos como fonte de realização e de construção de identidade, mas ao contrário do que afirma o autor, as participantes da pesquisa (Supervisora pedagógica 2, Professora 1 e Merendeira 2) os trazem como fatores desencadeadores de sofrimento psíquico, uma vez que, além de ficarem com a maior parte das tarefas, ainda não são reconhecidas como trabalhadoras reprodutivas. Cabendo lembrar que a ausência de tal reconhecimento gera implicações na identidade da mulher, haja vista que além de não se verem frente a novas possibilidades de ressignificação, tornamse também vulneráveis quanto à saúde mental, conforme reitera Dejours (2012), ao explicar que o trabalho, ao atravessar a via do reconhecimento, contribui para a construção da identidade dos sujeitos, identidade esta responsável pela proteção da saúde mental.
Sintetizando, pode-se dizer que, embora as egressas participantes não tenham demonstrado sinais de adoecimento no sentido psicopatológico, deixam claro o sentimento de incompreensão por parte dos companheiros, dado este que pareceu despertar-lhes o sentimento de serem injustiçadas. Uma vez que as colocam em condição de invisibilidade enquanto trabalhadora reprodutiva. Sentindo-se em condição de servidão, entretanto, não trazem questões que possam servir como fonte de libertação deste lugar. Dado este que faz perceber certa sensação de conformismo quanto à posição que ocupam, talvez por serem norteadas pelos estereótipos inerentes a mulher, advindos do imaginário social e do contexto onde se construiu enquanto sujeito, conforme aponta Hirata (2018).

Contudo, dada sensação de divisão quanto à identidade materna pode ser fruto deste cansaço vivenciado tanto na esfera do trabalho produtivo, já que precisam ser suficientemente boas no que fazem inerentes ao serviço prestado ao município, além das atividades reprodutivas, uma vez que para estas além da cobrança tangível ao papel que exerce em casa (trabalho real), precisam também lidar com a insegurança no que diz respeito aos julgamentos sociais (trabalho prescrito/ideal). Tendo em vista que não podem deixar a desejar em suas atribuições, já que assim seriam reprovadas-incompreendidas enquanto mães, trabalhadoras e mulheres.

\section{A maternidade como possibilidade de transformação profissional}

Dejours (2012) revela que o trabalho vivo consiste não apenas em produzir, mas também em transformar o existir do próprio sujeito trabalhador. Neste sentido, ao buscar identificar as possíveis transformações que as trabalhadoras encontraram em suas atividades profissionais, após o retorno da licença maternidade, as entrevistadas deste estudo demonstraram atribuir à maternidade uma possibilidade de transformação, tanto no que tange ao olhar para as colegas de trabalho, no sentido de percebê-las também como mães, além de profissionais. Demonstrando compreenderem que 
tal fenômeno faz com que passem a vislumbrar o outro também como um sujeito conflitante, dotado de limites em sua realidade existencial, como pode-se verificar na afirmação da entrevistada Berçarista 1:

Antes se alguém faltava no trabalho porque o filho ficou doente eu falava, tá, mas... e ai? O que a Instituição tem a ver com isso? Hoje não, como mãe sei a dor que é, sei o que passam. (Berçarista 1).

Diante de tal afirmação, pode-se pensar que mediante a construção da identidade materna ao imbricar-se no sofrimento da separação da filha fez com que a identidade profissional desta trabalhadora fosse ressignificada de modo mais "preocupado". No sentido de levar a preocupação com a filha também para com as crianças atendidas nas unidades, levando a empenhar ainda mais para com a responsabilidade no desenvolvimento das crianças. Contudo, tal transformação também é compartilhada por outras trabalhadoras, que também acreditam que o retorno da licença maternidade, bem como o processo de tornarem-se mães, como um todo, as fez "melhores", como pessoas e profissionais, no sentido de até mesmo atribuírem às crianças mais preocupações no que tange aos cuidados, conforme se verifica nas narrativas:

Eu vivia só para mim e isso era sem dúvida muito mais fácil. Antes eu me preocupava com minha rotina, mas era diferente, porque depois que tive eles, mudou minhas preocupações emocionais, comportamentais e profissionais também. Eu falo isso, porque depois que me tornei mãe percebi que já amava muito meus alunos, só que agora o sentimento é muito diferente. Se eu vejo que estão em perigo, se estão em risco, me atino muito mais. (Supervisora pedagógica 1).

Depois que a gente se torna mãe o olhar muda totalmente, a gente passa a tratar as crianças de um modo diferenciado. Não dá para fazer para eles o que não quero para os meus, eu acho que o olhar fica diferenciado! Eu acho que ser mãe, além de transformar a vida da gente como pessoa, também contribui positivamente para nosso trabalho na educação. (Berçarista 2).
Buscando compreender tais discursos, Dejours (2012) afirma que o trabalho passa de sofrimento a prazer quando sua qualidade é reconhecidae os desânimos e contradições adquirem sentido. Nesse contexto, todo esse sofrimento não somente prestou uma contribuição à organização do trabalho, mas também, em compensação, no caso destas participantes, fez com que tornassem diferentes do que eram antes do reconhecimento de sua contribuição, bem como das vivências maternas pessoais antes realizadas. Para fins de melhor compreensão, segue como ilustração a verbalização da participante Berçarista 1:

Olha, mudou muita coisa, agora que sou berçarista, além de ser mãe, mas que também senti o que é me separar, consigo me colocar no lugar destas mães. Sei como é ruim sofrer, nós sofremos ele e eu, então assim, cuido muito mais, aumentou minha responsabilidade, tudo está outra coisa. Porque me coloco no lugar delas, mas também penso muito nas crianças, elas precisam de uma atenção maior, um carinho de quem está cuidando. Para mim a segunda maternidade veio para dar mais responsabilidade, então foi muito bom, uma transformação positiva. (Berçarista 1).

Embora as participantes acima e ao lado apresentadas abordem a maternidade como uma possibilidade de transformação positiva, no sentido de provocá-las a ressignificarem suas identidades construídas ao longo de trajetórias profissionais, por outro lado, a maternidade também é compreendida como fator limitante para o trabalho, já que tal acontecimento faz com que as trabalhadoras se sintam divididas e, muitas vezes, se deparam com uma crise de identidade, conforme pode ser verificado na afirmativa da Supervisora pedagógica 1 a seguir:

Profissionalmente falando, isso me fez perceber que a gente não consegue dar conta de fazer horário extra, que muitas vezes é necessário para cumprir a demanda. A gente não dá conta de tudo depois de ter filhos pequenos. Tento fazer o melhor que posso para conciliar os dois lados, mas no fim um dos dois acaba 
ficando prejudicado. No começo é pior, porque as preocupações devido à separação faz ficar muito difícil, mas aos poucos a gente vai entendendo que eles também precisam ter um tempo longe da gente, isso é bom até para o desenvolvimento deles. Ai a gente passa a reorganizar a vida e tenta fazer o melhor que pode, mas tem horas que me perco, tem dia que não sei se sou mãe, supervisora, ou mulher! (Risos). (Supervisora pedagógica 1).

Os discursos a seguir, trazidos por outras mulheres participantes, também coadunam com a vivência realizada pela participante anterior (Supervisora pedagógica 1):

Eu levava muito trabalho para casa, ainda levo, mas bem menos que antes. Antes eu fazia tudo que dava na escola e o que não dava eu levava para casa, mas depois que ela nasceu fui levando cada vez menos. Até porque antes de ser mãe eu vivia o trabalho dia e noite, na correria da escola o que não dava para ser feito eu achava que tinha que levar para casa. Mas depois que elas nasceram tudo mudou, por que ai além de ter marido e casa para arrumar, eu passei a tê-las para dar banho, preparar a alimentação, dar afeto e tudo isso sem ter ninguém para me ajudar. (Supervisora pedagógica 2 ).

Tal achado vem ao encontro do que já foi identificado por Rodrigues e Sapucaia (2016), ao defenderem que a chegada de um filho interfere tanto positiva quanto negativamente na vida da mulher e, neste caso, as atividades profissionais tendem a ficar em segundo plano devido à dinâmica da rotina "tumultuada" da vida pessoal, tal como afirma a participante Berçarista 2 a seguir:

O trabalho em si não mudou muito, porque antes eu atuava com desenvolvimento e hoje ainda faço isso. Era prazeroso trabalhar e ver a criança desenvolvendo, mas isso continua gratificante como sempre foi. O que mudou foi que ficou mais tumultuado, antes eu tinha um filho, hoje tenho três, me canso muito mais, porque tenho que cuidar o tempo todo, mas o trabalho continua igual. (Berçarista 2).

Para fins de compreensão da trajetória das participantes, faz-se analisá-las a partir das reflexões de Dejours (2012), ao apontar que a significação profunda do trabalho, bem como o valor das atividades exercidas para cada indivíduo é própria, sendo criada a partir das técnicas particulares desenvolvidas por cada sujeito. A seguir, encontrase uma narrativa inerente à ressignificação da atividade profissional, segundo uma vivência particular de uma das trabalhadoras participantes:

Eu comecei a olhar para as crianças de um modo diferente. Porque quando a gente não é mãe a gente não entende, hoje presto atenção no desenvolvimento deles, como calça um tênis, coisas que eles precisam de uma ajuda e que antes eu pensava, nossa que criança devagar (risos). Passei a preocupar mais com a alimentação deles, procuro reparar se estão comendo certinho, porque aqueles que não estão eu procuro avisar a mãe. Hoje do jeito que me preocupo com os meus, preocupo com os delas também. (Auxiliar de educação inclusiva 1).

Diante da afirmativa desta profissional, pode-se compreender que o olhar diferenciado que atribui ao seu filho pode se constituir no fator que auxiliou no modo de compreender a diferença vivenciada pelas crianças com as quais atua como auxiliar de educação inclusiva. Demonstrou que o fato de ver seu filho se desenvolvendo como um sujeito singular faz com que também acredite na potência do desenvolvimento das crianças escolares com alguma deficiência.

As profissionais a seguir, Auxiliar de serviços gerais, Professora 1 e Professora 2, assim como a já apresentada anteriormente Auxiliar de educação inclusiva 1 , dialogam com Dejours (2012), no sentido que apontam transformação no manejo profissional, uma vez que ao tornarem-se mães, apropriaram de outros saberes que podem contribuir para o aprimoramento dos cuidados com os escolares, conforme salientam:

Então estou pensando aqui, parece que depois de mãe a gente passa a preocupar mais com as crianças que a gente atende também, olhar para elas e a família acaba sendo diferente. Antes eu pensava que o serviço fosse só limpar e pronto, mas agora como mãe penso que não 
dá para fazer para as crianças aquilo que não quero para minhas filhas. Mas isso é uma coisa que vem acontecendo comigo desde as outras gestações, eu venho aprendendo com cada uma a ser melhor até como profissional. (Auxiliar de serviços gerais).

Como que é interessante, porque antes eu buscava muito mais teoria, mas depois que me tornei mãe vejo como é diferente cuidar de filhos dos outros. Hoje eu cuido deles do modo como quero que cuidem dos meus, dou muito mais carinho, tenho cuidado e tudo dando bem mais atenção, muito diferente mesmo. (Professora 1).

Para mim trabalhar com educação depois de ser mãe mudou muito, nossa mudou demais! Porque a forma da gente ver as crianças fica diferente, porque ai a gente passa a viver os dois lados. Hoje vivo o lado da educadora que está aqui na escola, mas também sei como é o lado da família que fica em casa deixando os outros cuidarem dos filhos. Então,... não tem como ficar igual, muda tudo mesmo. Eu fui entender a dor de uma mãe ao deixar um filho chorando aqui depois de ser mãe, então eu acho que uma pessoa que ainda não teve um filho não sabe como é isso, não consegue entender tanto. Porque minha menina mesmo, quando levei para escolinha, a professora dela que não é mãe falava: "não deixa ela, tem que deixar chorar, uma hora ela vai parar". Bom, para ela falar isso é fácil, porque ela não sabe qual é meu sentimento, ela só irá saber quando ela for mãe! Falar que a criança vai parar de chorar e que é uma fase é fácil, ela vê o lado da profissional e isso eu também sei, mas só que para a mãe, por mais que ela saiba que o filho chora por mãe, isso dói! Então mudou, hoje aqui eu vejo e vivo os dois lados! Às vezes olho para cara de preocupada, ou culpada que a mãe faz aqui, da vontade de falar também, fica tranquila, porque isso é mesmo assim, vai passar, mas falo de um outro modo, por que sei que não é fácil, eu vivo os dois lados. (Professora 2).

Por fim, pode-se afirmar que observando a relação que se desdobra do conflito entre maternidade e inserção no mercado de trabalho, apropriando-se da perspectiva dejouriana, o que antes foi compreendido de maneira ambivalente, como perda aos olhos das egressas participantes, representada pelo sofrimento em detrimento da separação do bebê, pode ser ressignificado como ganho, uma vez que consideram como dado de aprimoramento pessoal/profissional o fato de terem se tornado mães. Tal descoberta, no entanto, pode ser fruto de uma forma subjetiva que encontraram para serem reconhecidas, visto a ausência apresentada dos suportes oferecidos à mãe trabalhadora dentro e fora da instituição de trabalho.

\section{Considerações Finais}

Sabendo que o objetivo principal desta pesquisa esteve pautado na reflexão acerca da percepção de trabalho para mulheres após a licença maternidade, no tocante à relação entre maternidade e trabalho, embora as análises realizadas buscassem privilegiar o olhar dejouriano inerente ao trabalho, cabe advertir que o referido autor não discute maternidade, dado este que fez com que outros autores pudessem dialogar com os interesses e resultados obtidos pela pesquisa.

Pensando acerca do vir a ser mãe, compreendendo que os achados desta investigação são analisados como processos para além das vivências fisiológicas, as participantes de modo quase que geral manifestaram falas que levam a percepção da noção de maternidade como algo a ser revisto. Revisão decorrente de essas mães apontarem o ser mãe como uma realização pessoal, uma experiência única dotada de sentido e afeto, porém vislumbram a realidade e percebem que vir a ser mãe não é um processo que se desvela somente nutrido de prazer, mas que, ao contrário da ideia romântica ditada pelas maternalistas, tornar-se mãe implica em trabalho. Dado que leva a perceber as implicações que o tornar-se mãe gera na trajetória de cada uma das participantes, seja no âmbito pessoal, já que se definem como preocupadas com os cuidados para com os filhos(as), seja como profissional, visto que acabam por ampliar a carga de trabalho e o sentimento de divisão regido pela dicotomia mãe versus trabalhadora acaba por atravessá-las o tempo todo. 
Este aspecto evidencia que, em suas falas, foi notoriamente identificado que o fato de aliarem as atribuições das atividades reprodutivas com o trabalho produtivo faz com que se sintam angustiadas. Afeto que emerge, uma vez que não se veem amparadas e nem reconhecidas pelos companheiros por tais funções, já que este sentimento não aparece em nenhum discurso, além de que, ao mesmo tempo, encontramse desejosas por mais tempo junto aos filhos e também para que possam realizar vivências para elas mesmas. Visto que mediante as atividades realizadas precisam engenhosamente encontrar um modo inteligente, porém subjetivo de dar conta destas múltiplas funções, já que tal feito, além de oferecer mais qualidade na relação mãebebê, acabaria por levar a mulher a sentir-se mais segura em suas múltiplas jornadas.

Dadas percepções levam a compreender a relevância da divisão equivalente de tarefas da mulher/trabalhadora com seus maridos e/ ou companheiros, haja vista que mediante os inúmeros papeis e a sobrecarga que estes às trazem, compreende-se que as mulheres acabam por nutrirem um sentimento de despersonalização. Em outras palavras, sentem-se como se não fossem mais elas, pois atravessadas pelo sentimento de angústia quanto aos cuidados maternos, aliado às cobranças sociais e profissionais que recebem, sua saúde mental acaba por ser comprometida e em um fluxo de inseguranças que experimentam, sendo que o sentimento prevalente é o de perda de identidade, já que nestes meandros não sabem se ao modo como estão realizando suas atividades garantem a elas um lugar de reconhecimento pessoal e profissional. Fatores estes que as levam a exigirem ainda mais de si mesmas quanto ao que podem potencializar de modo satisfatório.

Contudo, é imperativo lembrar que a não participação masculina nas tarefas domésticas é notoriamente compreendida como um fruto da estrutura patriarcal e do discurso machista que permeia as relações socioculturais em nossa sociedade, o que leva certos homens a nomearem trabalho reprodutivo como coisas de mulheres.
Dessa forma, para que estas mulheres/mães/ trabalhadoras possam desenvolver suas atividades, faz-se necessário suporte social eficaz, já que não sabendo exatamente o lugar que ocupam, ou a qual mais se dedicar, pode ser que venham a experimentar sinais psicopatológicos como ansiedade ou depressão. Assim, tais divisões de tarefas passam a servirem como uma prevenção ante ao adoecimento psíquico, um modo profilático de cuidar da mulher como um todo.

Tendo em vista que embora as egressas participantes não tenham demonstrado sinais de adoecimento psicopatológico, evidenciam o sentimento de incompreensão por parte dos companheiros, dado este que pareceu fazê-las sentirem injustiçadas, uma vez que as colocam em condição de invisibilidade quanto trabalhadora reprodutiva. Sentindo-se em condição de servidão, entretanto, não trazem questões que possam atuar como fonte de libertação deste lugar. Dado este que faz perceber certa sensação de conformismo quanto à posição que ocupam, talvez por serem norteadas pelos estereótipos inerentes a mulher, advindos do imaginário social e do contexto no qual foram se constituindo enquanto sujeitos.

Contudo, dada sensação de divisão quanto à identidade materna pode ser fruto deste cansaço vivenciado tanto na esfera do trabalho produtivo, já que precisam ser suficientemente boas no que fazem inerentes ao serviço prestado ao município, além das atividades reprodutivas. Uma vez que para estas, além da cobrança tangível ao papel que exercem em casa, precisam também lidar com a insegurança no que diz respeito aos julgamentos sociais (trabalho prescrito/ideal), tendo em vista que não podem deixar a desejar em suas atribuições, já que, assim, seriam reprovadas ou incompreendidas como mães, trabalhadoras e mulheres.

Pensando no trabalho como um fator promotor de identidade e aliando esta função ao tornar-se mãe, em seus discursos, as participantes demonstraram compreender a maternidade como uma possibilidade de transformação, no que tange o olhar para as colegas de trabalho. Isto, no 
sentido de percebê-las também como mães, além de suas atividades profissionais, demonstrando conceberem que tal fenômeno faz com que passem a vislumbrar o outro também como um sujeito conflitante, dotado de limites em sua realidade existencial. Dado este que as levam a compreender o sofrimento também experimentado por seus pares, haja vista que na condição de mães e trabalhadoras que experimentam o sofrimento da insegurança imbricada nos dois papeis, faz com que tenham mais aceitação no modo de ser e estar trabalhadora das colegas como um todo.

Apontaram que a preocupação oriunda da condição materna fez com que também se preocupassem mais com as crianças que cuidam, podendo assim, pensar que uma vez ressignificada a identidade de mulher, também acabam por engenhosamente encontrarem um caminho subjetivo, ou seja, próprio de dar um novo colorido ao seu fazer profissional.

Neste sentido, pode-se afirmar que a maternidade, bem como o sofrimento inerente ao retorno ao trabalho, no caso do grupo entrevistado por essa pesquisa, prestou às mulheres participantes não apenas um papel de fortalecedor de suas identidades, mas também atuou como promotor de reconhecimento. Um reconhecimento tanto da importância do serviço prestado por esta quanto no que toca a compreensão do modo de ser dos pares e dos cuidados atribuídos às crianças.

\section{Agradecimentos}

A Coordenação de Aperfeiçoamento de Pessoal de Nível Superior (CAPES) que financiou essa pesquisa.

\section{Referências}

ANDRADE, C. J.; PRAUN, L. D.; AVOGLIA, H. R. C. Estratégias defensivas utilizadas frente à conciliação maternidade e trabalho: um olhar para as profissionais da educação. Brazilian Journal of Development, São José dos Pinhais, v. 6, p. 3543635452, 2020.
ANDRADE, C. J.; PRAUN, L. D.; AVOGLIA, H. R. C. O sentido do trabalho para mulheres após a licença maternidade: um estudo com profissionais de educação. Semina: Ciências Sociais e Humanas, Londrina, v. 39, n. 2, p. 147-158, 2018.

ÁVILA, M. B. O tempo do trabalho doméstico remunerado: entre cidadania e servidão. In: ABREU, A. R. P.; HIRATA, H.; LOMBARDI, M. R. (org.). Gênero e trabalho no Brasil e na França: perspectivas interseccionais. São Paulo: Boitempo Editorial, 2016.

BARDIN, L. Análise de conteúdo. São Paulo: Edições 70, 2016.

BEAUVOIR, S. O segundo sexo. Rio de Janeiro: Nova Fronteira, 1980.

BENINCASA, M.; ANDRADE, C. J.; SOUZA, F. C. A paternidade participativa na perspectiva de mulheres egressas da licença maternidade: uma reflexão interseccional. In: BENINCASA, M.; ROMAGNOLO, A. N.; HELENO, M. G. V. (org.). Maternidade, parentalidade e conjugalidade: novas perspectivas em psicologia perinatal. Curitiba: CRV, 2020. p. 275-292.

BRASIL. Decreto-Lei n. ${ }^{\circ} 5.452$, de $1^{\circ}$ de maio de 1943. Aprova a Consolidação das Leis do Trabalho. Diário Oficial da União, Rio de Janeiro, RJ, 9 ago. 1943, Seção 1, p. 11937. Disponível em: https://bit. ly/2BJ715i. Acesso em: 19 jun. 2020.

CARNUT, L. Pesquisa social ou pesquisa qualitativa? Uma dis(des)cu(constru)ss(ç)ão em pauta na saúde coletiva. Saúde em Debate, Rio de Janeiro, v. 43, p. 170-180, 2019.

DEJOURS, C. Trabalho vivo: trabalho e emancipação. Brasília: Paralelo Quinze, 2012.

FABBRO, M. R. C.; HELOANI, J. R. M. Mulher, maternidade e trabalho acadêmico. Investigación y Educación en Enfermería, Medellín, v. 28, n. 2, p. 176-186, jul. 2010.

GARCIA, C. F.; VIECILI, J. Implicações do retorno ao trabalho após licença-maternidade na rotina e no trabalho da mulher. Fractal: Revista de Psicologia, Niterói, v. 30, n. 2, p. 271-280, 2018.

HIRATA, H. Gênero, patriarcado, trabalho e classe. Revista Trabalho Necessário, Niterói, v. 16, n. 29, p. 14-27, 2018. 
IBGE. Censo 2010. Disponível em: https://bit. ly/39BIkEi. Acesso em: 29 jun. 2020.

INSTITUTO DE PESQUISA ECONÔMICA APLICADA - IPEA. Mulheres e trabalho: breve análise do período 2004-2014. Brasília: Ministério do Planejamento, Orçamento e Gestão, 2016.

KRAUSE, L. I. Mulher, trabalho e maternidade: demandas no retorno da licença-maternidade. 2017. Dissertação (Mestrado Profissional em Saúde da Mulher, Criança e Adolescente) - Universidade Católica de Pelotas, Pelotas, 2017. Disponível em: https://bit.ly/3jT03f6. Acesso em: 29 jun. 2020.

LIMA, S. C. C. O trabalho do cuidado: uma análise psicodinâmica. Revista Psicologia Organizações e Trabalho: rPOT, Florianópolis, v. 12, n. 2, p. 203215, 2012.

ROCHA-COUTINHO, M. L.; COUTINHO, R. R. Mulheres brasileiras em posições de liderança: novas perspectivas para antigos desafios. Economia Global e Gestão, Lisboa, v. 16, n. 1, p. 61-79, 2011.

RODRIGUES, C.; SAPUCAIA, M. Proteção à maternidade: uma reflexão sobre apaziguamento e sedimentação das desigualdades entre homens e mulheres. Revista da ABET, Curitiba, v. 15, n. 1, p. 22-32, jan. /jun. 2016.

TURATO, E. R.; BASTOS, R. A.; VIEIRA, A. S. L.; WEBER, A. As pesquisas qualitativas: desafios de sua cientificidade. In: BICUDO, M. A. V.; COSTA, A. P. (org.). Leituras em pesquisa qualitativa. São Paulo: Editora Livraria da Física, 2019. v. 1, p. 135-144.

VANALli, A. C. G.; BARHAM, E. J. Após a licença-maternidade: a percepção de professoras sobre a divisão das demandas familiares. Psicologia \& Sociedade, Belo Horizonte, v. 24, n. 1, p. 130138, jan. /abr. 2012. 